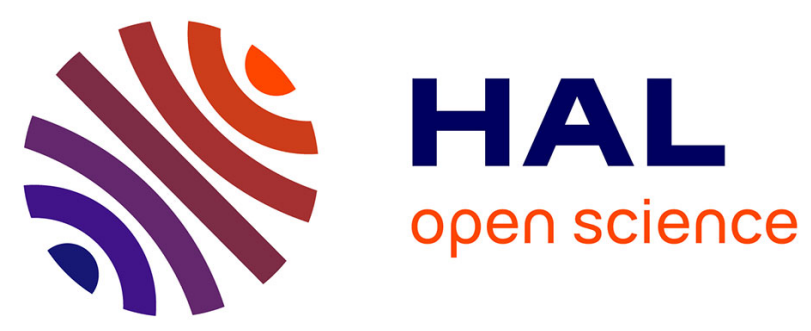

\title{
Topotactic Fibrillogenesis of Freeze-Cast Microridged Collagen Scaffolds for 3D Cell Culture
}

Clement Rieu, Cleo Parisi, Gervaise Mosser, Bernard Haye, Thibaud Coradin, Francisco M Fernandes, Lea Trichet

\section{- To cite this version:}

Clement Rieu, Cleo Parisi, Gervaise Mosser, Bernard Haye, Thibaud Coradin, et al.. Topotactic Fibrillogenesis of Freeze-Cast Microridged Collagen Scaffolds for 3D Cell Culture. ACS Applied Materials \& Interfaces, 2019, 11 (16), pp.14672-14683. 10.1021/acsami.9b03219 . hal-02124299

\section{HAL Id: hal-02124299 \\ https://hal.sorbonne-universite.fr/hal-02124299}

Submitted on 14 Nov 2019

HAL is a multi-disciplinary open access archive for the deposit and dissemination of scientific research documents, whether they are published or not. The documents may come from teaching and research institutions in France or abroad, or from public or private research centers.
L'archive ouverte pluridisciplinaire HAL, est destinée au dépôt et à la diffusion de documents scientifiques de niveau recherche, publiés ou non, émanant des établissements d'enseignement et de recherche français ou étrangers, des laboratoires publics ou privés. 


\title{
Topotactic Fibrillogenesis of Freeze-Cast Microridged Collagen Scaffolds for 3D Cell Culture
}

\author{
Clément Rieu, Cleo Parisi, ${ }^{\circledR}$ Gervaise Mosser, ${ }^{\circledR}$ Bernard Haye, Thibaud Coradin, ${ }^{\circledR}$ \\ Francisco M. Fernandes, ${ }^{*}$ (i) and Léa Trichet* ${ }^{*}$
}

Sorbonne Université, CNRS, Laboratoire de Chimie de la Matière Condensée de Paris, Pierre and Marie Curie Campus, 4 place Jussieu, 75252 Paris Cedex 05, France

Supporting Information

ABSTRACT: Type I collagen is the main component of the extracellular matrix (ECM). In vitro, under a narrow window of physicochemical conditions, type I collagen self-assembles to form complex supramolecular architectures reminiscent of those found in native ECM. Presently, a major challenge in collagen-based biomaterials is to couple the delicate collagen fibrillogenesis events with a controlled shaping process in non-denaturating conditions. In this work, an ice-templating approach promoting the structuration of collagen into macroporous monoliths is used. Instead of common solvent removal procedures, a new topotactic conversion approach yielding self-assembled ordered fibrous materials is implemented. These collagen-only, non-cross-linked scaffolds exhibit uncommon mechanical properties in the wet state, with a Young's modulus of $33 \pm 12 \mathrm{kPa}$, an ultimate tensile stress of $33 \pm 6 \mathrm{kPa}$, and a strain at failure of $105 \pm 28 \%$. With the help of the ice-patterned microridge features, normal human dermal fibroblasts and $\mathrm{C} 2 \mathrm{C} 12$ murine myoblasts successfully migrate and form highly aligned populations within the resulting three-

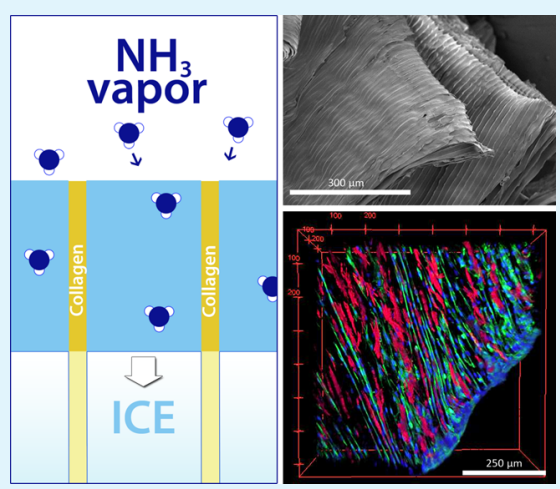
dimensional (3D) collagen scaffolds. These results open a new pathway to the development of new tissue engineering scaffolds ordered across various organization levels from the molecule to the macropore and are of particular interest for biomedical applications where large-scale 3D cell alignment is needed such as for muscular or nerve reconstruction.

KEYWORDS: biomaterials, collagen fibrillogenesis, ice templating, 3D cell culture, macroporous scaffold

\section{INTRODUCTION}

The fibrillar state of collagens is a key parameter for the mechanical properties of extracellular matrices (ECMs) and their interaction with cells. ${ }^{1,2}$ Being able to achieve fibrillogenesis in tissue-mimicking scaffolds is therefore of paramount importance to develop new materials for tissue engineering applications. In vivo, the synthesis and assembly of type I collagen into organized fibrillar structures are mediated by cells. ${ }^{3}$ In accordance with the local requirements of the tissue, collagen biosynthesis results in remarkably different suprafibrillar architectures, ranging from highly aligned domains in tendon ${ }^{4}$ to the cholesteric arrangement of fibers in the bone. ${ }^{5}$ Reproducing these architectures in vitro requires a thorough control over the physico-chemical conditions before, during, and after fibrillogenesis. ${ }^{6}$ However, the assembly of collagen fibers into ordered domains in the micron range is in many cases insufficient as scaffolds also need a precise structuration at the macroscopic scale. To date, a vast range of techniques have been proposed to shape fibrillar collagen into dense materials, such as extrusion, ${ }^{7}$ electrochemical alignment, ${ }^{8}$ cellmediated gel compaction, ${ }^{9}$ and plastic compression, ${ }^{10}$ among others, with encouraging results already obtained in vivo. Still, these techniques often prove to be unsuitable for additional internal structuration of the materials. In particular, porosity, a key morphological feature in biomaterials as it determines the diffusion of nutrients and waste and can promote cell guidance, remains difficult to be controlled, except by top-down threedimensional (3D) methods. ${ }^{11}$ In this context, freeze-casting, a technique initially developed for the structuration of colloidal suspensions for the elaboration of ceramic materials, ${ }^{12}$ has been adapted to produce scaffolds based on collagen and other biopolymers for tissue engineering purpose. ${ }^{13-15}$ This technique enables to create oriented macroporous scaffolds (i.e., with pores larger than $50 \mathrm{~nm})^{16}$ from colloidal suspensions or polymer solutions by means of directional freezing, followed by ice sublimation. ${ }^{17}$ Upon anisotropic cooling, an oriented segregation occurs between the newly formed ice and the solutes and/or particles initially present in the solution/suspension. Tuning of pore sizes and choice between isotropic or anisotropic global structures with anisotropic substructures can be achieved by playing with different parameters such as solution composition, freezing kinetics, and temperature gradient. ${ }^{18}$ For collagen-based scaffolds, static freeze-casting of type I collagen solutions with concentrations between 5 and $20 \mathrm{mg} \cdot \mathrm{mL}^{-119-22}$ led to pore sizes ranging from $20^{22}$ to $200 \mu \mathrm{m}$ at the upper extremity 

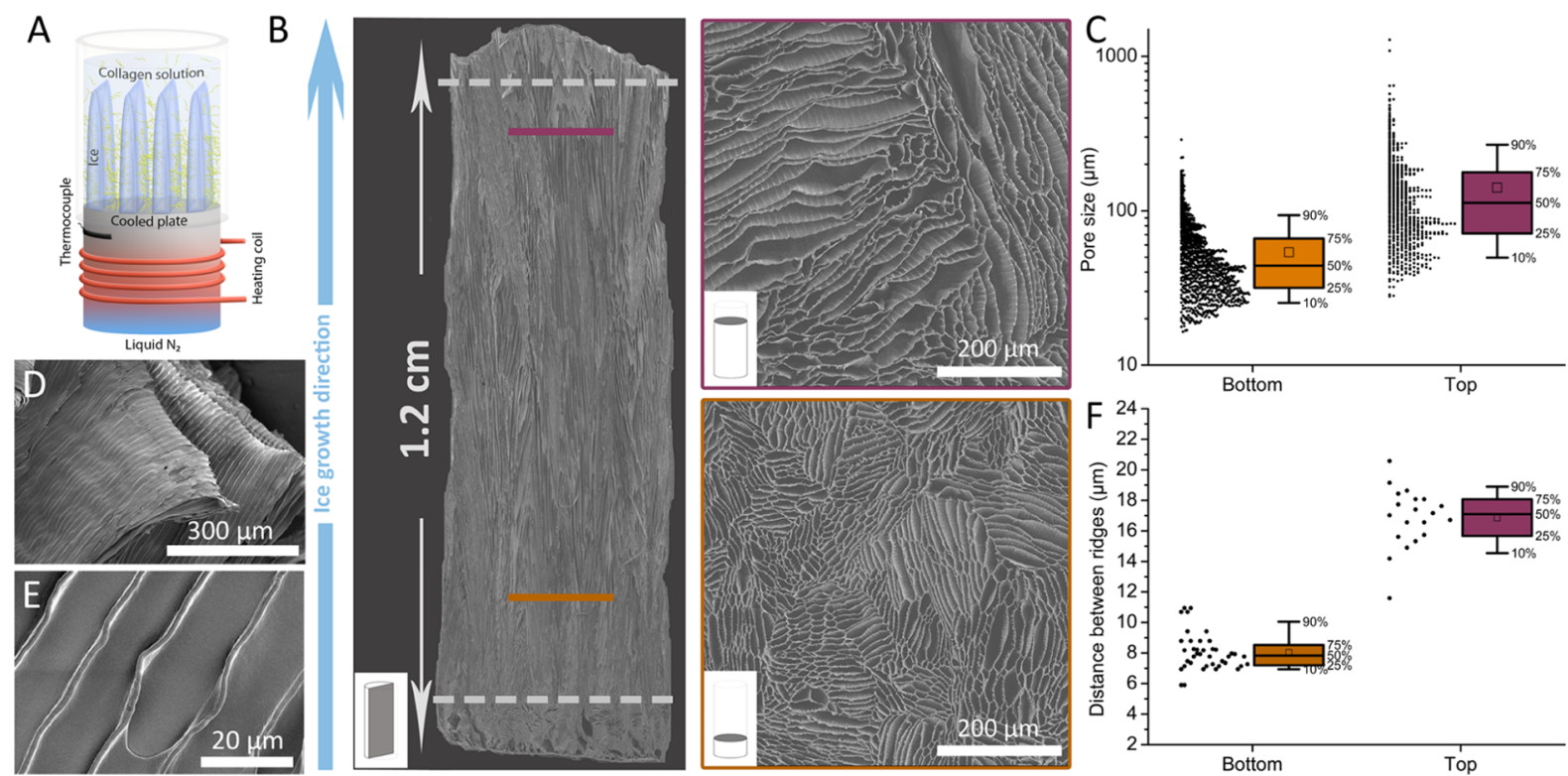

Figure 1. Collagen freeze-casting and resulting structures of the lyophilized scaffold. (A) Schematic of the setup enabling the growth of the ice crystals and the subsequent concentration of collagen in walls because of phase segregation. (B) SEM reconstitution from multiple images of the longitudinal section of the scaffold resulting from freeze-casting, observed after lyophilization (left) and two transverse sections at different heights showing different pore sizes (right). The central part delineated by the dashed lines was used for cell culture. (C) Pore size quantification by Feret maximum diameter measurement of the two cross sections displayed in (B). (D,E) SEM images of the pore walls patterned with regular parallel ridges running all along the main axis of the scaffold, observed at two different magnifications. $(\mathrm{F})$ Quantification of the distance between ridges in the two different sections displayed in (B).

of the scaffold. ${ }^{21}$ Although these works have been successful in building porous materials out of acid-soluble type I collagen, they have failed in inducing fibrillogenesis of the obtained porous collagen materials. As a result, the obtained scaffolds were water-soluble or mechanically weak and required subsequent cross-linking, either by physical $^{19,23}$ or by chemical $^{24,25}$ methods. The stiffness of the resulting materials usually ranges from a few $\mathrm{kPa}(10-30 \mathrm{kPa}$ in compressive testing $)^{26,27}$ to almost $1 \mathrm{MPa}(0.5-0.8 \mathrm{MPa}$ by tensile testing $)^{20,28}$ in dry state. Following rehydration, the moduli drop to values ranging from a few hundred $\mathrm{Pa}$ to a few $\mathrm{kPa}$ ( 1 $\mathrm{kPa}$ in hydrated condition vs $10 \mathrm{kPa}$ in dry state by compressive testing, ${ }^{26} 0.2 \mathrm{kPa}$ vs $30 \mathrm{kPa}$ in compression, and $2 \mathrm{kPa}$ by tensile testing in hydrated condition ${ }^{27}$ ). As an alternative, fibrillogenesis of collagen can be induced before freezing. Using uncontrolled freezing process in cylinders with a high aspect ratio, Lowe et al. demonstrated that comparable mechanical properties could be achieved in non-cross-linked fibrillar collagen aligned materials compared to cross-linked non-fibrillar scaffolds. ${ }^{29}$ Fibrillogenesis prior to freezing was also used by Murray et al. in their successful clinical test to avoid risks associated with the use of chemical crosslinkers. ${ }^{30-32}$ However, so far, no fibrillar macroporous collagen material presenting a controlled architecture at multiple length scales and of oriented porosity has been achieved.

In this work, we have developed a new method to trigger type I collagen fibrillogenesis after freeze-casting, coupling the macroporous structure induced by the ice crystals to the selfassembly of the collagen molecules into fibers. To develop a topotactic process preserving the structure obtained by freezecasting, we designed a protocol based on ammonia vapors at low temperature for two purposes: (1) to induce collagen selfassembly by raising the $\mathrm{pH}$ inside the scaffold ${ }^{33,34}$ and (2) to slowly melt ice crystals secondary to freezing point depression. ${ }^{35}$ The obtained scaffolds are characterized structurally before, during, and after the process to examine the effects of the freeze-casting and the topotactic process. Tensile tests are performed to investigate the role of collagen self-assembly in structural integrity, and a comparison is made with lyophilized and further cross-linked (CXL) scaffolds. The ability of the scaffolds to be colonized and to align cells is then tested by seeding in vitro normal human dermal fibroblasts (NHDFs) and C2C12 myoblasts.

\section{MATERIALS AND METHODS}

2.1. Collagen Solution. Collagen I was extracted from young rat's tail tendons. After thorough cleaning of tendons with phosphatebuffered saline (PBS) $1 \times$ and $4 \mathrm{M} \mathrm{NaCl}$, tendons were dissolved in 3 $\mathrm{mM} \mathrm{HCl}$. Differential precipitation with $300 \mathrm{mM} \mathrm{NaCl}$ and $600 \mathrm{mM}$ $\mathrm{NaCl}$, followed by redissolution and dialysis in $3 \mathrm{mM} \mathrm{HCl}$, provided collagen of high purity as confirmed by sodium dodecyl sulfate polyacrylamide gel electrophoresis. A final collagen concentration of $3.7 \pm 0.3 \mathrm{mg} \cdot \mathrm{mL}^{-1}$ was determined using hydroxyproline titration. Acid-soluble type I collagen stock solution was aliquoted and stored at $4{ }^{\circ} \mathrm{C}$. Prior to use, stock solution was centrifuged at $3000 \mathrm{~g}$ at $10{ }^{\circ} \mathrm{C}$ in Vivaspin tubes with a $300 \mathrm{kDa}$ filter cutoff to reach a final concentration of $40 \mathrm{mg} \cdot \mathrm{mL}^{-1}$.

2.2. Freeze-Casting. Concentrated collagen solutions $(0.2 \mathrm{~mL}, 40$ $\mathrm{mg} \cdot \mathrm{mL}^{-1}$ ) were poured into cylindrical molds. After centrifugation, each mold was individually processed on a home-made freeze-casting setup made of a copper rod partially immersed in liquid nitrogen, with a heating coil and a thermocouple to monitor the temperature of the cooled plate as previously described (Figure 1A). ${ }^{36}$ The collagen solution was cooled at a $-5{ }^{\circ} \mathrm{C} \cdot \mathrm{min}^{-1}$ rate from 20 to $-60{ }^{\circ} \mathrm{C}$. The final temperature was kept at $-60{ }^{\circ} \mathrm{C}$ until the sample was entirely frozen. Samples were then kept in a freezer at $-80{ }^{\circ} \mathrm{C}$ until further use.

2.3. Collagen Fibrillogenesis and Sample Preparation. Fibrillogenesis of collagen was performed in different steps. First, the frozen samples were kept at $0{ }^{\circ} \mathrm{C}$ under ammonia vapors for $48 \mathrm{~h}$ to ensure pre-fibrillogenesis induced by the $\mathrm{pH}$ increase. As ammonia 
vapors reach the ice/collagen surface, ice starts to melt because of the freeze point depression of the water/ammonia liquid mixture that is formed at the interface. Throughout the $48 \mathrm{~h}$ contact time, where the sample is kept in a closed vessel of around $350 \mathrm{~mL}$ with approx. 10 $\mathrm{mL}$ of $30 \%$ ammonia solution, the ice front progressively recedes and the whole sample is exposed to ammonia. Samples (equivalent to approximately $0.2 \mathrm{~mL}$ of initial volume) were then transferred to tubes floating on $2 \mathrm{~L}$ deionized (DI) water at $37{ }^{\circ} \mathrm{C}$ and kept for $24 \mathrm{~h}$ to remove ammonia. Samples were subsequently dipped into $40 \mathrm{~mL}$ PBS $5 \times$ to complete fibrillogenesis at neutral $\mathrm{pH}$ for at least 2 weeks. The resulting scaffolds were $12-15 \mathrm{~mm}$ long with a diameter between 5 and $6 \mathrm{~mm}$.

2.4. Scanning Electron Microscopy. Structural observations and quantitative analysis of the obtained structures were performed on dry samples lyophilized after freeze-casting. All the samples were coated with a $10 \mathrm{~nm}$ gold layer before observation under the Hitachi $\mathrm{S}$ $3400 \mathrm{~N}$ SEM (operating at $3 \mathrm{kV}$ ). Image analysis was performed using Image J software to determine the size of the pores on transverse sections cut across the length of the cylindrical scaffolds. Automatic image analysis was conducted after images were binarized to quantify the characteristic dimensions of the pores. Statistics on the length of major axis were obtained based on at least 600 different pores using Feret diameter measurement of individual pores (maximum caliper). The statistical description of the distance between the observed ridges was based on 20 individual measurements obtained from three different pictures of the two transverse sections considered. The whole scaffold longitudinal reconstitution was composed from 15 pictures taken at $\times 27$ magnification and superimposed using Adobe Photoshop.

The characterization of hydrated collagen samples after fibrillogenesis was conducted by cross-linking overnight in paraformaldehyde (PFA) $4 \%$ vol at $4{ }^{\circ} \mathrm{C}$, followed by $1 \mathrm{~h} 2.5 \%$ glutaraldehyde in cacodylate buffer at $4{ }^{\circ} \mathrm{C}$. Samples were subsequently dehydrated using ethanol baths with increasing concentrations and then supercritically dried.

2.5. Transmission Electron Microscopy. Hydrated samples were cross-linked with PFA, glutaraldehyde, and osmium tetroxide 4 wt $\%$. They were subsequently dehydrated using baths with increasing concentrations in ethanol, progressively transferred to propylene oxide, and incorporated in araldite resin prior to sectioning. Dry control samples obtained after freeze-casting and lyophilization (no fibrillogenesis) were dipped in ethanol prior to the same protocol of inclusion with propylene oxide and araldite. After inclusion of samples in araldite, $500 \mu \mathrm{m}$ thin sections were stained with toluidine blue and observed under a Nikon Eclipse E600Pol microscope equipped with a $2.5 \times, 10 \times$, and $40 \times$ objective and a DXM 1200 CCD camera as a first observation. Built-in cross-polarizers were used to observe the birefringency of thin sections. Then, $70 \mathrm{~nm}$ ultrathin sections (Leica microtome) were contrasted with uranyl acetate and observed on a transmission electron microscope (FEI Tecnai Spirit G2) operating at $120 \mathrm{kV}$ to observe the ultrastructural collagen features. Images were recorded on a Gatan CCD camera.

2.6. Cross-Linked Samples. The CXL samples were produced by lyophilization of the frozen samples after freeze-casting and subsequent immersion in ethylene dichloride (EDC)/ $\mathrm{N}$-hydroxysuccinimide (NHS) solution (molar ratio 2.5 M EDC/M NHS, with 6 mM EDC per gram of collagen) for $4 \mathrm{~h}^{26}$

2.7. Mechanical Testing. Tensile testing was done on an Instron 3343 machine equipped with a $10 \mathrm{~N}$ load cell and a watertight column to perform the tests in hydrated conditions. The traction was exerted on rectangular sections cut from the center of the samples by means of a vibration microtome (HM 650V Thermo Scientific), with a blade vibrating at $100 \mathrm{~Hz}$ and a cutting speed of $2 \mathrm{~mm} \cdot \mathrm{min}^{-1}$. The $1.5 \mathrm{~mm}$ slices obtained were kept in PBS to ensure equilibration with the solution. The tests were performed at a velocity of $1 \mathrm{~mm} \cdot \mathrm{min}^{-1}$ along the freezing direction. The samples were held vertically in PBS solution between Velcro straps glued to the clamping jaws of the machine holders. The initial cross section of each slice was precisely measured by taking a picture of this cross section on a calibrated contact angle machine (Krüss, DSA30) and by measuring the surface using Image $\mathrm{J}$ software.

2.8. Degradation Test. Degradation test was performed by immersion of fibrillated (FBL) and CXL scaffolds in triplicates in 2 $\mathrm{mL}$ of collagenase solution $(50 \mathrm{U} / \mathrm{mL}, 100 \mathrm{mM}$ Tris $\mathrm{pH} \mathrm{7.5,20 \textrm {mM }}$ $\mathrm{CaCl}_{2}$ ) and incubation at $37^{\circ} \mathrm{C}$. At the different time points, $100 \mu \mathrm{L}$ of each solution was sampled and replaced by $100 \mu \mathrm{L}$ of fresh collagenase solution. Concentration of degraded collagen in solutions was measured by hydroxyproline titration. After total loss of integrity of the FBL scaffolds, the entire solution was collected with the rest of samples, and both were centrifuged. The pellets were rinsed three times with DI water and lyophilized. The mass of the remaining scaffold was then weighed on a precision balance.

2.9. Cell Culture. Cell culture was performed on FBL whole samples cut at each end to remove the characteristic irregular porosity zone because of supercooling during freeze-casting, as well as on CXL scaffolds. Samples were first rinsed several times for at least $24 \mathrm{~h}$ in cell culture medium. Cells were then seeded on top of the scaffolds lying horizontally in the medium in a 12 -well culture plate, which allowed the investigation of cell penetration and migration inside the scaffolds. NHDFs (PromoCell) at passage 13 were seeded on both FBL and CXL scaffolds, with 110000 cells per well, and left 3 weeks in culture, changing medium [low-glucose Dulbecco's modified Eagle's medium (DMEM), GIBCO, 10\% fetal bovine serum, GIBCO] every other day. Longitudinal slices of the scaffolds were also seeded at the same time with similar conditions. C2C12 cells (ATCC) were seeded on FBL scaffolds at P13 with 66000 cells per well. Two conditions were used. Half were left in proliferation medium (high-glucose DMEM, GIBCO, 20\% fetal bovine serum, GIBCO) for 11 days in culture, whereas the other half was cultivated during the same period of time but with differentiation medium (high-glucose DMEM, GIBCO, $2 \%$ horse serum, GIBCO) for the last 4 days. All cell culture conditions were carried out in triplicates.

2.10. Fluorescence and Second Harmonic Generation Microscopy. At the end of the culture, and at day 1 and day 9 for NHDFs, the samples were rinsed with PBS $1 \times$ and left overnight in 4\% PFA to ensure complete cross-linking of the whole scaffolds. Slices $(1.2 \mathrm{~mm})$ were then cut from the fixed samples using a vibration microtome. For both types of cells, fluorescent labeling of the nuclei [4',6-diamidino-2-phenylindole (DAPI), Invitrogen] and the actin filaments (Alexa Fluor 488 phalloidin, Invitrogen) was performed. Additional labeling of $\mathrm{C} 2 \mathrm{C} 12$ with MF-20 hybridoma mouse IgG2B primary antibody and Alexa Fluor 546 goat anti-mouse IgG2B secondary antibody (Invitrogen) was used to investigate their differentiation. Ki67 labeling (Abcam Ab15580) was performed for proliferation assay.

Extensive observations of the samples were carried out under a fluorescence microscope (Axio Imager D.1, Zeiss). Further observations were conducted on a Leica SP5 upright confocal, multiphoton laser scanning microscope, which enabled the combination of fluorescence and second harmonic generation (SHG) observations.

2.11. Alamar Blue Assay. Along with the $\mathrm{FBL}$ and $\mathrm{CXL}$ samples seeded with NHDFs and observed by fluorescence microscopy, six replicates of each type of scaffold were seeded and placed into new wells at day 1 to only take into account cells adhering on scaffolds. Alamar blue assay was performed at different time points by addition of $80 \mu \mathrm{L}$ of $0.1 \mathrm{mg} \cdot \mathrm{mL}^{-1}$ resazurin solution to $720 \mu \mathrm{L}$ of fresh whole medium and incubation for $4 \mathrm{~h}$. Solutions were then sampled and measured with a fluorimeter. Reduction ratio corresponds to the ratio between the intensity of the sampled solution and the intensity of a fully reduced one (both corrected from baseline).

\section{RESULTS}

3.1. Ice Templating of Macroporous Collagen Scaffolds. The home-built freeze-casting setup enabled the control of ice crystal growth in $40 \mathrm{mg} \cdot \mathrm{mL}^{-1}$ type I collagen solutions and thus the successful templating of the resulting scaffold. After lyophilization, a porous scaffold with lamellar pores oriented along the freezing direction and presenting a 


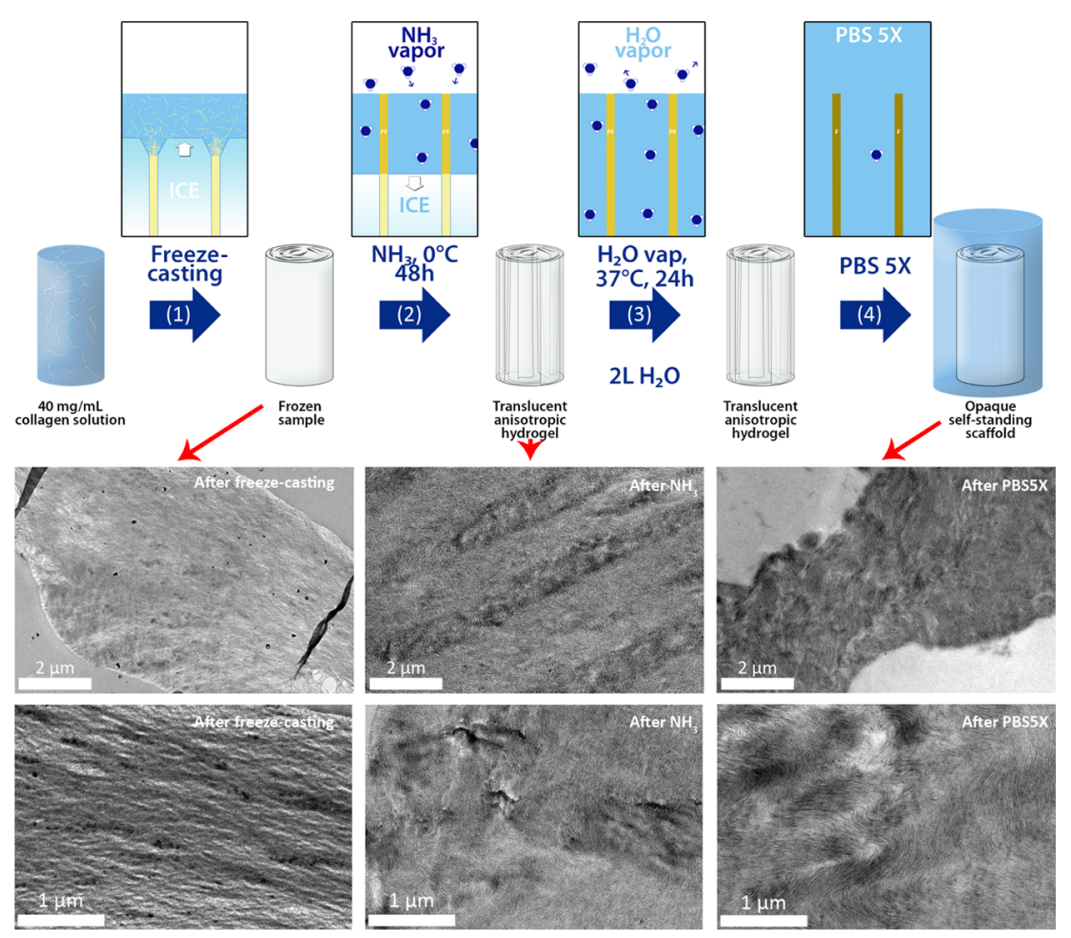

Figure 2. Process from the freeze-cast sample to the fibrillar scaffold. Center: Schematic of the scaffold after each step from solution to the fibrillar scaffold. Top: Schematic of the transformation occurring during each step. The collagen (yellow) solution is first ice-templated (1) and then kept at $0{ }^{\circ} \mathrm{C}$ for $48 \mathrm{~h}$ under ammonia-saturated atmosphere to melt the ice and trigger prefibrillogenesis of the collagen (2). Ammonia is then desorbed from the sample by placing it in an open vessel floating on $2 \mathrm{~L}$ of DI water at $37{ }^{\circ} \mathrm{C}$ (3), and the scaffold is finally placed into PBS $5 \times$ to ensure its complete fibrillogenesis. Bottom: TEM observations of the scaffold after steps (1), (2), and (4) and at two different magnifications.

gradient of pore size was obtained (Figure 1B). At the bottom of the scaffold, pores were arranged in small domains of parallel sheets 25-95 $\mu \mathrm{m}$ wide (10th to 90th percentile) (Figure 1B bottom right, Figure 1C orange), randomly distributed in 2D (Supporting Information, Figure S1A,C). Following ice growth direction, the domains of parallel sheets broadened (Supporting Information Figure S1B,E) and pore major axis increased between 50 and $270 \mu \mathrm{m}$ (10th to 90th percentile), with some pores reaching up to $1.3 \mathrm{~mm}$ (Figure 1B top right, Figure 1C violet). A substructure made of parallel ridges also ran along the same direction of the scaffold (Figure $1 \mathrm{D}, \mathrm{E})$. The ridges only appeared on one side of a wall and were periodically spaced, with the period ranging from 6.9 to $10.0 \mu \mathrm{m}$ (10th to 90th percentile), at the bottom, to 14.5-18.9 $\mu \mathrm{m}$ (10th to 90th percentile) at the top of the scaffold (Figure $1 \mathrm{~F})$.

3.2. Topotactic Fibrillogenesis of Ice-Templated Collagen Scaffolds. After ice templating (Figure 2 step 1), the samples were kept for $48 \mathrm{~h}$ under ammonia vapors at $0{ }^{\circ} \mathrm{C}$, turning the frozen scaffold into a translucent hydrogel (Figure 2 step 2). After being placed under a water-saturated atmosphere at $37{ }^{\circ} \mathrm{C}$ for $24 \mathrm{~h}$ (Figure 2 step 3), the hydrogel remained translucent and turned opaque upon further dipping into PBS $5 \times$ (Figure 2 step 4). Transmission electron microscopy (TEM) images of samples after freeze-casting showed liquid-crystal-like local organization of collagen as well as the absence of fibrils (Figure 2 bottom left). After ammonia treatment, small fibrils were visible displaying some degree of local organization, reminiscent of the previously described liquid-crystal organizations of collagen ${ }^{37-39}$ (Figure 2 bottom middle). At the end of the process, after steps 3 and 4, the previously observed dense organized areas of small fibrils (Supporting Information, Figure S2A,B) coexist with domains comprising larger fibrils (Figure 2 bottom right, Supporting Information, Figure S2C). Pores remained open after this process (Supporting Information, Figure S3A) as opposed to dipping freeze-cast scaffold directly after step 1 into a neutral buffer such as PBS $10 \times$ that resulted in occluded pores (Supporting Information, Figure S3B).

3.3. Scaffold Morphology and Mechanics. The opaque water-stable self-standing scaffolds obtained at the end of the above described process were $12-15 \mathrm{~mm}$ long and 5-6 $\mathrm{mm}$ wide (Figure 3A). SHG imaging of slices of scaffolds gave strong signal characteristic of aligned and/or fibrillar collagen. SHG enabled the 3D reconstitution of the aligned porous structure of the scaffolds (Figure 3B). Scanning electron microscopy (SEM; Figure 3C,D) confirmed these observations by showing open pores with ridges similar to the ones observed on freeze-cast scaffolds, evidencing the topotactic nature of the process. In addition, some collagen fibers could be visualized inside the pores in certain areas of the scaffold. Observation of thin sections under cross-polarizers showed birefringency of the scaffold ridges, with a maximum transmission at the same angle for all the ridges (Figure 4A,B and Supporting Information, Figure S3A, for comparison without a polarizer). In TEM pictures, scaffold walls present different structural domains, with tightly packed and aligned small fibrils (Figure 4C, Supporting Information, Figure S2A) and less dense domains with larger fibrils that display wave patterns (Figure 4D, Supporting Information Figure S2C). Fibers outside the wall present the characteristic $67 \mathrm{~nm} \mathrm{D}$ banding (Figure 4D, Supporting Information, Figure S2B).

Mechanical properties were measured by performing tensile tests in PBS $1 \times$ on longitudinal slices from different samples. Figure 5A displays a typical stress versus strain curve with corresponding photos of the sample in Figure 5B. The sample 

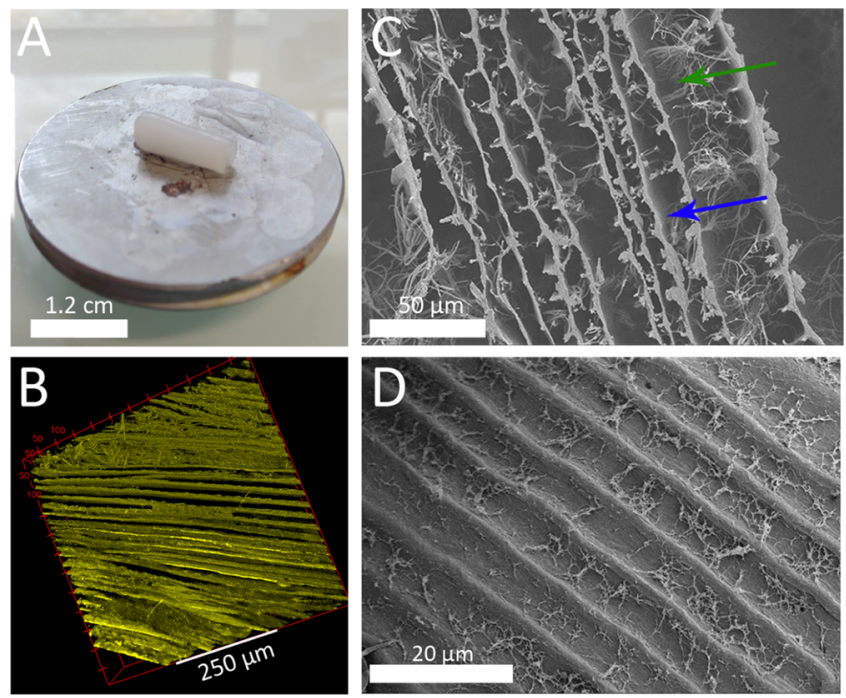

Figure 3. Resulting self-standing scaffolds presenting fibrillar collagen with preserved pore and microridge structures. (A) Picture of the opaque self-standing scaffold after the fibrillogenesis protocol. (B) 3D spatial reconstitution of a slice of scaffold observed under confocal SHG. (C,D) SEM pictures of a slice of the scaffold (blue arrow: a ridge, green arrow: a self-standing fiber).
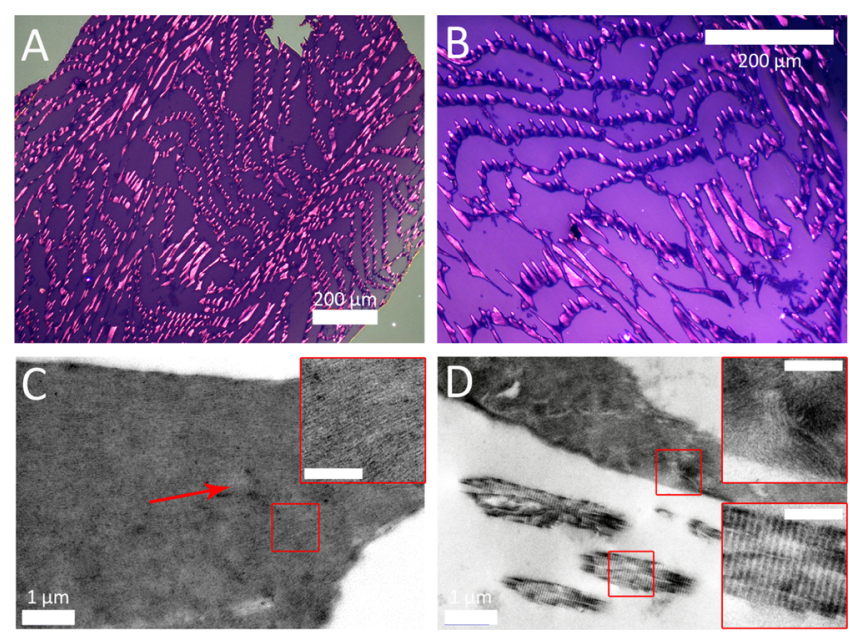

Figure 4. Resulting microstructure of the fibrillar scaffold. (A,B) Images of semithin sections of the scaffold observed under crosspolarizers. (C,D) TEM images of a section of the scaffold displaying different sizes and densities of fibers (red arrow: direction of the fibers on the picture). Insets: scale bar $=200 \mathrm{~nm}$.

undergoes a linear deformation (Figure 5B1,2) to approximately $105 \pm 28 \%$ strain and $33 \pm 6 \mathrm{kPa}$ stress in average with a Young's modulus reaching $33 \pm 12 \mathrm{kPa}$ (Figure 5C). After this point, it finally cracks at several levels provoking the delamination of the sample (Figure 5B3,4).

As a control, CXL nonfibrillated scaffolds were produced using the typical protocol of lyophilization and EDC/NHS cross-linking of scaffolds after freeze-casting. ${ }^{26}$ This process resulted in scaffolds with a different aspect, with a white dense core and a transparent shell (Figure S4). CXL scaffolds were much stiffer, almost reaching the MPa range $(E=0.81 \pm 0.35$ $\mathrm{MPa}$ ), but also much more brittle, failing at $13 \pm 4 \%$ elongation.

An accelerated biodegradation test with collagenase at $50 \mathrm{U} /$ $\mathrm{mL}$ was performed on both types of scaffolds. After $9 \mathrm{~h}$, the
FBL scaffolds were completely destroyed with small parts still in solution (ca. 70\% degradation), whereas CXL scaffolds retained their shape (degradation limited to 30\%) (Figure S5).

3.4. In Vitro 3D Cell Culture. 3.4.1. Normal Human Dermal Fibroblasts. NHDFs were seeded and cultured on entire scaffolds to observe cell colonization (Figure 6A). After being cultured for 3 weeks, they show high proliferation on the scaffold surface, forming a dense layer of cells. Most cells seem aligned along the principal direction (direction of freezing) as shown in Figure 6A1. When observing the outside of a thin longitudinal upper slice, cells are found to be aligned in the same direction as the ridges (Figure 6A2). This is confirmed by confocal microscopy coupled with SHG, as seen in Figure $6 \mathrm{~A} 3$ and in Supporting Information, Movie S1A, where cells, which actin filaments are labeled, all adopt a fusiform shape aligned along the main direction of the scaffold. Recovering internal longitudinal slices of the cellularized scaffolds allowed for the study of deeper colonization. A first and most obvious cell population originated from cell migration through the open pores at each extremity of the scaffold (Figure 6A4 top left). Cells migrated inside the scaffold over a distance up to $1.5 \mathrm{~mm}$, aligned along the main direction (Figure 6A5), and adopted fusiform shapes with long cytoplasmic protrusions (Figure 6A6). It was observed that a deeper colonization involving a higher number of cells occurred from the extremity with the larger pores (top of the scaffold, as displayed in Figure 1B) compared to the one with the smaller pores (bottom of the scaffold). A second type of colonization also occurred through the sides of the scaffold, resulting in a density gradient of cells toward the inner part of the scaffold (Figure 6A4 bottom) over a distance up to $500 \mu \mathrm{m}$. In this region, fibroblasts aligned along the main direction as shown in Figure 6A7 and in Supporting Information, Movie S1B. Confocal microscopy enabled to observe cells in the plane of a wall and to show their alignment along the ridges (Figure 6A8, Supporting Information, Movie S1C). Noticeably, when similar NHDF cultures were performed on precut central longitudinal slices, high proliferation and significant cell alignment were also observed (Figure 6B1,2).

In parallel, nonfibrillated cross-linked scaffolds were seeded and analyzed for comparison purposes, with metabolism tests and fluorescence microscopy observations at multiple time points (Figure S6). For both types of scaffolds, the reduction ratio of Alamar blue increased similarly for the first 2 weeks and then slowed down (Figure S6A). The reduction ratio was higher for FBL during the first week, with a 3.5-fold difference at day 1 ( $p=0.0152$, Mann-Whitney) and a 2-fold difference at day 6 ( $p=0.0022$, Mann-Whitney) between FBL and CXL, while differences between the two scaffolds were nonsignificant from day 9 and CXL reduction ratio even seems to overtake FBL (ns).

At day 1, observation of the two types of scaffolds (in triplicates) showed a clear difference in outer cell density between FBL and CXL (Figure S6B1-4) but no inner cell colonization for any type of scaffold. At day 9, both types of scaffolds were covered with a confluent, or close-to-confluence, cell layer (Figure S6B5,7). Inner colonization could be observed for both types of scaffolds (Figure S6B6,8). In CXL scaffolds, the core-shell structure often led to the apparition of macroscopic cavities (Figures S7 and S6B8, blue arrow) between the white core (W) and the transparent (T) shell, heavily colonized by cells (Figure S6B8, red arrow). At day 20, the transparent part of CXL scaffolds exhibited a 

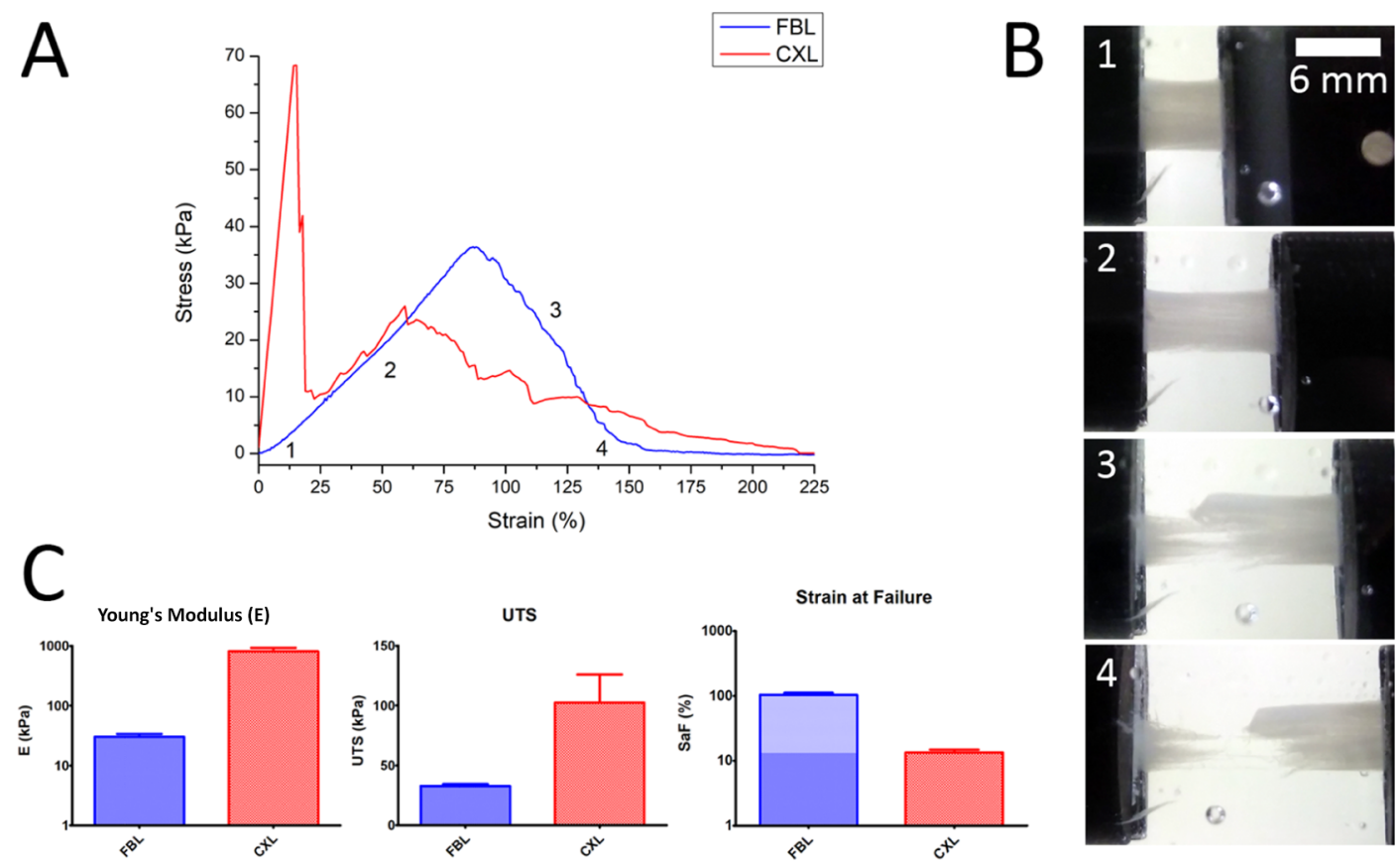

Figure 5. Mechanical properties of the scaffold after fibrillogenesis (FBL) or after cross-linking (CXL). (A) Stress vs strain curve of a $1.5 \mathrm{~mm}$ thick slice of each scaffold pulled at a velocity of $1 \mathrm{~mm} \cdot \mathrm{min}^{-1}$. (B) Pictures of the FBL scaffold corresponding to the numbers indicated on the curve. (C) Young's modulus (left), ultimate tensile stress (middle), and strain at failure (right) of both FBL and CXL scaffolds. Error bars $=2 \times$ SD.

similar trend as FBL, with high cellular density on the outside (Figure S6B11 vs Figure S6B9) and the observation of two types of colonization, through the sides (radial, Figure S6B12 vs Figure S6B10) and through open pores at the extremities (axial, Figure S6B15 vs Figure S6B13,14). Interestingly, the white core does not seem to be colonized internally, but a high cellular density can be observed around it (Figure S6B16). Ki67 immunolabeling was performed to assess the proliferative state of NHDFs in both types of scaffolds. It appeared that cells at the outer part of the scaffolds (Figure S6B2,4,5,7,9,11) as well as inside CXL cavities (Figure S6B16) expressing Ki67 were in significant amount (around 30\%), while they were scarce inside the pores (Figure S6B6,10,12-15).

3.4.2. C2C12 Myoblasts. Similar colonization experiments were carried out using $\mathrm{C} 2 \mathrm{C} 12$ murine myoblast cell line. Cells were seeded on whole scaffolds for 11 days. Half of the samples were left in proliferation medium, whereas the other half was supplemented with differentiation medium for the last 4 days instead of high serum concentration proliferation medium. No significant differences could be observed between the two conditions. In each case, high proliferation and alignment of myoblasts was observed outside the scaffold (Figure 7A1,2), in the same way as that with NHDF cells. Some parallel myotubes expressing heavy myosin chains (MF20) could sometimes be observed as indicated by immunostaining (Figure 7A). The same internal colonization patterns as that for NHDFs could also be observed from both scaffold extremities and sides but over a longer distance, reaching 2.5 $\mathrm{mm}$ from the extremities and $1.5 \mathrm{~mm}$ from sides compared to $1.5 \mathrm{~mm}$ and $500 \mu \mathrm{m}$ for NHDFs, respectively (Figure 7B1,2). Some myotubes positive for MF20 were observed aligned to the main direction of the scaffold (Figure 7C1,2). Confocal microscopy reconstitutions as shown in Figure $7 \mathrm{D} 1,2$ and Supporting Information Movie S2A,B illustrate both types of colonization: from an extremity (Figure 7D1 and Supporting Information Movie S2A) and from a side (Figure 7D2 and
Supporting Information Movie S2B). They also enable the observation of the anisotropic shape of the myoblasts.

\section{DISCUSSION}

4.1. Scaffold Structuration and Properties. To address the current challenge of preparing scaffolds combining fibrillar collagen and oriented porosity, we have developed a new topotactic procedure to induce collagen fibrillogenesis after freeze-casting and obtain scaffolds presenting anisotropic features at multiple length scales. The protocol enables the production of stable scaffolds in physiological conditions without cross-linking or dehydration process and therefore appears relevant to mimic collagen structures observed in native tissues while preserving collagen bioactivity.

A first challenge addressed was to induce the selforganization of type I collagen molecules into liquid-crystal phases within the frozen materials. In collagen solutions at 3 $\mathrm{mM} \mathrm{HCl}$, isotropic/anisotropic phase transition was reported to occur at ca. $50 \mathrm{mg} \cdot \mathrm{mL}^{-1} .{ }^{37}$ Here, while the initial collagen concentration is smaller $\left(40 \mathrm{mg} \cdot \mathrm{mL}^{-1}\right)$, phase segregation due to ice crystallization locally concentrates collagen above the critical value, as confirmed by the observation of liquid-crystallike organizations after ice templating. In parallel, the ice crystal growth generated ridges parallel to the main axis. These are, to the best of our knowledge, the first reported ridges in collagen-based scaffolds obtained by directional freezing. Such features have been previously observed in porous ceramics, where they might even form bridges between lamellae. ${ }^{12}$ Microridged pores were also observed after freeze-casting chitosan solutions, with a regular spacing of approximately 10 $\mu \mathrm{m} .{ }^{14}$ These overgrown dendrites supposedly arise from local ice crystal tip splitting because of particle-interface interactions occurring in dense solutions. In fact, this phenomenon is highly dependent on the solvent nature and was not observed when using collagen solutions prepared in acetic acid (data not shown). 

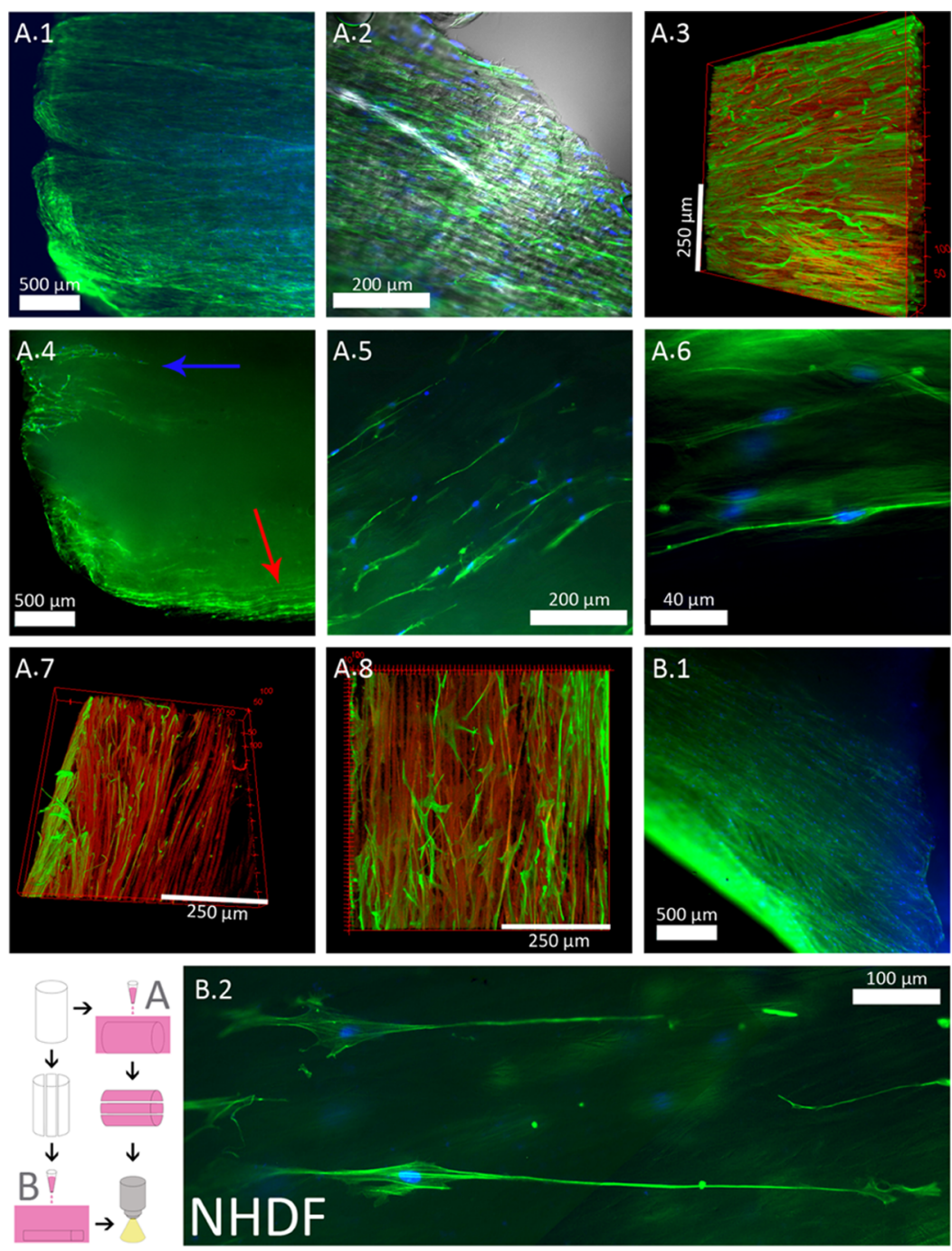

Figure 6. NHDF colonization of the whole scaffold (A) and central precut slice (B). (A1) Fluorescence microscopy image of NHDF proliferation on the outside of the scaffold. (A2) Fluorescence microscopy image of NHDF proliferation on the outside of the scaffold at higher magnification with the brightfield channel. (A3) SHG and fluorescence 3D reconstitution from confocal microscopy of the outer part of the scaffold (longitudinal upper slice) (corresponds to Supporting Information, Movie S1A). (A4-6) Fluorescence images of NHDFs inside the scaffolds at different magnifications (central slice). Blue arrow: cell colonization through open pores. Red arrow: cell density gradient from lateral colonization. (A7) SHG and fluorescence 3D reconstitution from confocal microscopy of the side of the scaffold with a cell density gradient (corresponds to Supporting Information, Movie S1B). (A8) Observation of cells and ridges on a wall (corresponds to Supporting Information, Movie S1C). (B1) Fluorescence image of a central slice of scaffold cut prior to seeding. (B2) Fluorescence image of the same sample with high magnification. Green: actin; blue: DAPI; red: collagen SHG signal. Visualization window for 3D reconstitutions: $591 \times 591 \mu \mathrm{m}$.

Our goal was to stabilize the sample with its hierarchical organization via collagen fibrillogenesis using a topotactic process, that is, without changing the structure and substructure of the walls and pores. Here, the term "topotaxis" strictly refers to the above definition used in the field of chemistry and not to the single-cell sensitivity to the topography gradient phenomenon introduced by Park et al., ${ }^{40}$ which was not addressed in the present work. Dipping the freeze-cast scaffold directly into a neutral buffer such as PBS $10 \times$ resulted in a loose material with occluded pores, indicating an unfavorable competition between collagen fibrillogenesis and dissolution (Supporting Information, Figure S3B). Similar results were obtained when scaffolds were lyophilized before being placed in the buffer medium. To circumvent this issue, we turned our attention to a gas-phase process using ammonia vapors. This strategy has been widely used to induce fibrillogenesis in concentrated type I collagen solutions at room temperature. ${ }^{33,34}$ In our case, using ammonia vapors presents another key advantage: it lowers the freezing temperature of ice. This freezing point depression allows to progressively achieve fibrillogenesis of the collagen within the walls of the sample kept at $0{ }^{\circ} \mathrm{C}$ (Figure 2 step 2). After $48 \mathrm{~h}$ under ammonia vapors, the recovered hydrogel was selfstanding and translucent, suggesting that small collagen fibrils had been formed. TEM images confirmed that liquid-crystal organization was preserved during fibrillogenesis. This assumption was supported by the observation of semithin sections under a polarized microscope showing birefringence. Two specific patterns stand out from the observations made: the alignment of fibrils on large domains, which can reach dimension above the tens of micrometers (Figure 4C and Supporting Information, Figure S2A), and the presence of wave or arch pattern (Figures 2 and 4D, and Supporting Information, Figure S2C). The first one would correspond to 

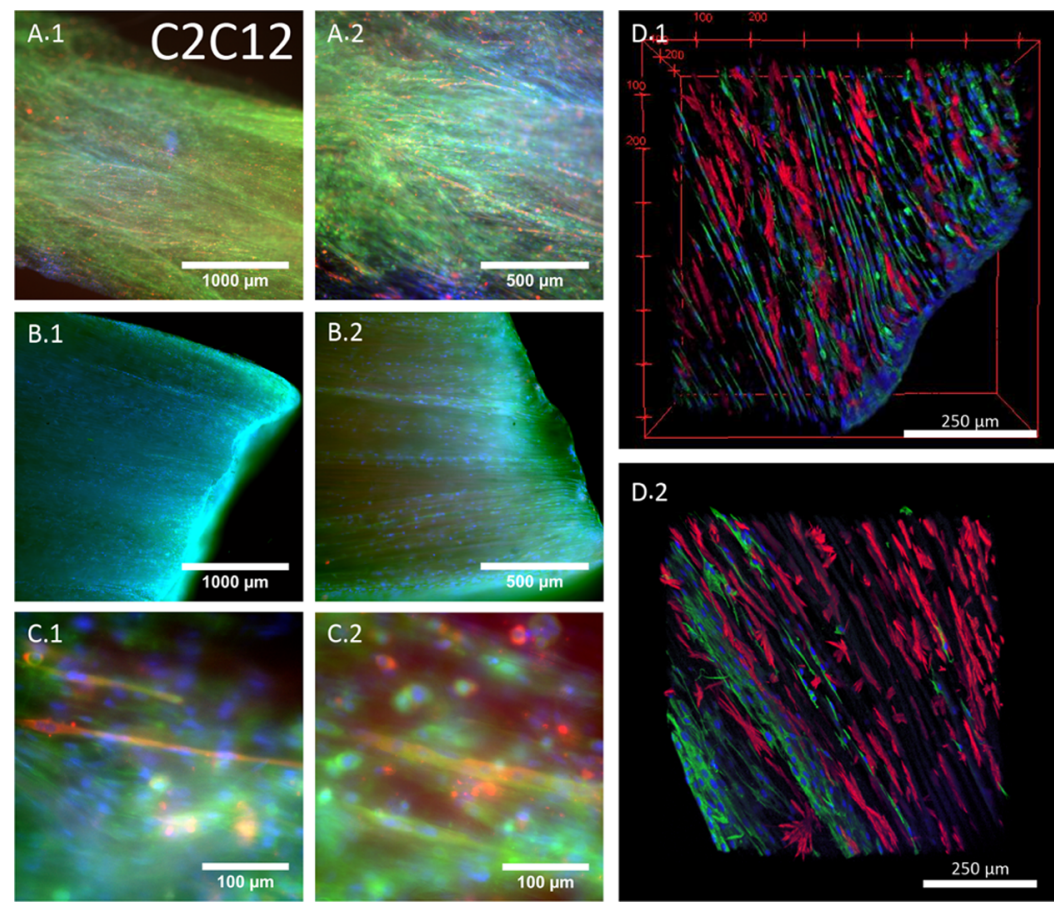

Figure 7. C2C12 myoblast colonization of the whole scaffold. (A1,A2) Fluorescence microscopy images of $\mathrm{C} 2 \mathrm{C} 12$ proliferation on the outside of the scaffold at two different magnifications. (B1,B2) Fluorescence microscopy images of $\mathrm{C} 2 \mathrm{C} 12$ proliferation on the inside of the scaffold at two different magnifications (longitudinal central slice). (C1) High-magnification images of myotube formation (longitudinal outer slice). (C2) Highmagnification images of myotube formation (longitudinal central slice). (D1) Confocal SHG/fluorescence 3D reconstitution of C2C12 colonization inside the scaffold from one of its extremities (longitudinal central slice) (corresponds to Supporting Information, Movie S2A). (D2) Confocal SHG/fluorescence 3D reconstitution of C2C12 colonization on a scaffold side (corresponds to Supporting Information, Movie S2B). For fluorescence 2D images: green: actin; blue: DAPI; red: MF20. For 3D reconstitutions: green: actin; blue: DAPI; red: SHG signal. Visualization window for 3D reconstitution: $738 \times 738 \mu \mathrm{m}$.

the stabilization of nematic phases, whereas the second pattern would correspond to cholesteric or precholesteric phases. ${ }^{38}$ Both phases have been previously observed in highly concentrated collagen solutions as well as in the stabilized fibrillary state. ${ }^{37,38}$ Comparison with the literature suggests that the high compaction of the network together with the small size of fibrils would correspond to collagen concentration higher than $300 \mathrm{mg} \cdot \mathrm{mL}^{-1} .39$

The following water/vapor step used to rinse off $\mathrm{NH}_{3}$ and decrease the $\mathrm{pH}$ of the aqueous phase turned out to be paramount to preserve an open porosity. Dipping the scaffold into PBS $5 \times$ directly after exposure to ammonia vapors (step 2) resulted in a swollen translucent scaffold with occluded pores. As the $\mathrm{pH}$ of the PBS solution increases to basic $\mathrm{pH}$ upon dipping the scaffold, which presents a high ammonia content, collagen molecules and fibrils bear a significant negative charge, ${ }^{41}$ which may impact fibrillar integrity and is likely to promote water uptake from the solution. In contrast, after the water/vapor step has allowed the decrease of ammonia content, the scaffold can be dipped into PBS $5 \times$ without significant change in $\mathrm{pH}$ and thus without destabilization. This strategy further favors the growth of fibrils, as evidenced in the TEM images. Noticeably, the macroscopic aspect change of the scaffold from translucent to opaque started instantaneously and could be followed by naked eye observation for a few hours. Nevertheless, the scaffold was left in the buffer medium for 2 weeks before use to ensure complete stabilized fibrillogenesis of the scaffolds as the collagen matrix can remodel for days after neutralization. ${ }^{42,43}$
For comparison, the CXL scaffolds produced by lyophilization and subsequent EDC/NHS cross-linking ${ }^{26}$ resulted in a core-shell structure, with a frequent dissociation between the core and the shell, and possible loss of porosity of the core as could be inferred by the absence of colonization inside this part. Comparison of the hydrated structure of the obtained CXL scaffolds with the data from the literature is not relevant because the concentration of $40 \mathrm{mg} \cdot \mathrm{mL}^{-1}$ used is much higher than the collagen concentrations commonly reported. $^{20,26-28,44-46}$

From a morphological perspective, the macroporous materials presented here could be compared to collagen sponges. However, collagen sponges lack the fibrillary structure attained here. Nevertheless, collagen sponges are still the most common form for collagen biomaterials used in clinical applications, such as the artificial skin graft INTEGRA. ${ }^{47}$ These materials are usually prepared by freezing a solution of collagen and removing water by lyophilization or by using an organic solvent. ${ }^{48}$ In the absence of collagen fibrillogenesis, the resulting sponges are mechanically weak and soluble in water, requiring additional cross-linking steps, ${ }^{44}$ such as the one performed for CXL controls. In the literature, resulting materials have typical Young's moduli of $10 \mathrm{kPa}$ in the dry state, which systematically decrease in the wet state. ${ }^{26,45}$ While mechanical properties can be improved by addition of glycosaminoglycan (GAG) and additional processing steps, ${ }^{27,46}$ the Young's modulus value of $33 \mathrm{kPa}$ obtained here is unprecedented for pure collagen hydrated macroporous scaffolds, which are 1-2 orders of magnitude higher. The Young's modulus close to $1 \mathrm{MPa}$ obtained for CXL scaffolds in 
wet conditions overtakes by far the reported values. Such difference for both scaffolds compared to the literature is likely due to the higher collagen concentration used in our study. Here, the cross-linking process makes the scaffolds stiff and brittle, while the characteristics of FBL scaffolds are closer to those of soft tissues, such as muscle. ${ }^{49}$

In the presence of collagenase, FBL scaffolds are degraded after $9 \mathrm{~h}$, which is in good agreement with similar tests on FBL collagen gels. ${ }^{34}$ CXL scaffolds retained their shape after $9 \mathrm{~h}$, even though $30 \%$ of the scaffold was degraded, in agreement with the literature. ${ }^{50}$

This emphasizes the benefits of our described protocol that allows for the preparation of chemically stable and mechanically strong collagen materials without any required additional cross-linking step. Moreover, these scaffolds can be easily optimized in terms of pore size and macroscopic mechanical properties by adjusting the collagen concentration $^{51}$ according to the targeted colonizing cells.

4.2. Guiding Properties for the Cells. The high anisotropy of the pores and the ridges substructure, parallel to the direction of freezing, makes the obtained scaffolds appealing to promote cell alignment, a feature highly sought after in tissue engineering, in particular for cells such as myoblasts, tenocytes, or neurons.

In our experiments, we observed an alignment of both $\mathrm{C} 2 \mathrm{C} 12$ and NHDF cells along the main direction of the scaffold inside and outside of the scaffolds. Cell alignment outside the scaffold may come from the outer grooves observed under SEM (Supporting Information, Figure S8). Inside, cell colonization occurs from both the extremities and the sides of the sample. In both cases, cells align along the freezing direction. Although the main migration route for cell colonization is considered to be the materials macroporosity, it should also be possible for NHDFs to migrate through the scaffold walls via collagen degradation/remodeling. ${ }^{52}$

The partial colonization of scaffolds' internal space without any physical constraints nor biochemical cues except the scaffolds' oriented porosity itself to guide the cells in is highly encouraging. Although migration from both ends of the material was evidenced, it was not possible to observe fully colonized channels. This may be explained by the kinetics of colonization: here, a migration of NHDFs over ca. $500 \mu \mathrm{m}$ was obtained after 11 days of culture, and C2C12 myoblasts could colonize the scaffolds over a three times larger distance. Comparable data for fibroblast or myoblast migration in $3 \mathrm{D}$ environments are scarce in the literature because the colonization rate is expected to depend on many parameters including exact matrix composition and stiffness. ${ }^{53}$ However, NHDFs seeded in diluted collagen hydrogels $\left(2 \mathrm{mg} \cdot \mathrm{mL}^{-1}\right)$ within microfluidic devices were reported to migrate at rates between 20 and $200 \mu \mathrm{m}$ per day. ${ }^{54,55}$ While our own measured rate (ca. $50 \mu \mathrm{m}$ per day) lies in this range, our system differs in the initial cell seeding conditions (i.e., preimmobilization vs adhesion), the absence of flow, as well as the size and orientation of the pores. Still, questions may be raised about the possibility to colonize the whole scaffold because of a possible lack of diffusion of nutrients, factors, and waste in the core of the scaffold in spite of the high porosity. Longer culture time and thorough follow-up of colonization over time may answer these questions. The colonization of our scaffolds might also be further improved by the adjunction of signaling biomolecules. ${ }^{56}$ It is interesting to note that cells inside the scaffolds, that is, in $3 \mathrm{D}$, expressed Ki67 in extremely scarce cases, on the opposite to cells in " $2 \mathrm{D}$ ", that is, cells outside the scaffold and in CXL scaffolds' large cavities. This would mean that cell colonies in pores originate mainly from multiple cells coming from the outside as opposed to a few cells proliferating once inside. This result highlights the profoundly different metabolic activity of $\mathrm{NHDH}$ according to the geometrical constraints imposed by the scaffold. In particular, the mismatch between pore size and cell size observed in CXL samples induces a $2 \mathrm{D}$-like proliferation behavior, whereas this behavior is not observed in FBL samples, where the differences in relative size between pore section and cell size are markedly smaller.

The effect of scaffold structuration on cell behavior has been previously studied for many different types of cells. Caliari et al. showed that anisotropic collagen-GAG scaffolds induced higher proliferation rate and metabolic activity of equine tendon cells, as well as better alignment, compared to isotropic counterparts. ${ }^{57}$ The size of the pores also had an effect on cell activity, in particular regarding cell entry into the scaffolds. The smallest pores, around $55 \mu \mathrm{m}$, induced limited cell penetration as compared to 152 and $243 \mu \mathrm{m}$ ones. This is in agreement with our observations of a higher number of cells and deeper colonization through the large pores (50-270 $\mu \mathrm{m}$ wide) compared to the small ones $(25-95 \mu \mathrm{m})$. Gonnerman et al. have shown that cardiomyocyte alignment and beating activity were enhanced on larger pore size constructs. ${ }^{58}$ However, tenocyte metabolic activity was reported as being more efficient with a smaller pore size. ${ }^{59}$ Thus, the optimal pore size depends on cell type and freeze-casting should offer the possibility to fine-tune it to the desired dimensions.

The generation of microridges regularly spaced on the scaffold walls and oriented parallel to the pore main axis appears to confer an additional advantage to our process as it favors cell alignment by topographical contact guidance. A similar observation was reported for freeze-cast chitosan scaffolds, which strongly favored the alignment of chick root dorsal neurites. ${ }^{14}$ A particularly striking result we obtained is the clear alignment of NHDF cells seeded on scaffold slices, that is, in pseudo-2D conditions. Indeed, surface patterning on either coated polydimethylsiloxane ${ }^{60,61}$ or poly(2-hydroxyethyl methacrylate $)^{62}$ substrates or from microgrooved collagen scaffolds $^{63}$ has been shown to increase the muscular cell alignment and the formation of myotubes, with the possibility to optimize the spatial periodicity of the features. ${ }^{60}$ Here, the secondary guidance provided by the ridges is intrinsic to our materials and can also be optimized depending on the targeted cells.

On the effect of topotactic fibrillogenesis compared to crosslinked scaffolds, two differences stand out. The first, as discussed above, is the preservation of the structure and thus the possibility to tailor the scaffolds for the cells, tuning freezecasting parameters. The CXL scaffolds were inhomogeneous, with different structures from the inside to the outside because of a lack of control during the cross-linking process. The second is the cell adhesion that was significantly higher during the first week of culture as demonstrated by the Alamar blue test. Fluorescence microscopy revealed much higher cell density outside the FBL scaffolds compared to CXL scaffolds. Cells however proliferated on CXL scaffolds until bridging the gap, as monitored by the Alamar blue test and observed at day 9. The difference in adhesion may be due to the fibrillar structure of the scaffold and/or its mechanical properties as well as due to a side effect of the cross-linking process. 
The oriented porous collagen scaffolds presented in our study could also open the road to new strategies for the in vitro development of larger skeletal muscle 3D tissues with aligned myofibers. The production of such artificial tissues relies on cell-mediated and -guided gel compaction ${ }^{64-66}$ and on the transfer of aligned cell sheets into hydrogels, ${ }^{67-69}$ among other techniques. In our study, the ability of $\mathrm{C} 2 \mathrm{C} 12$ cells to differentiate and merge into myotubes was evidenced with limited success. However, it is likely that a longer differentiation time would allow the formation of myotubes, particularly inside the scaffold where diffusion may delay the change of environment and thus differentiation. Still, this may not fully account for the low differentiation and the main hypothesis is the lack of other ECM components, such as laminin, that were shown to play a paramount role in muscle development. ${ }^{70}$ The here-presented scaffolds could then be improved with the addition of these other ECM proteins to the initial collagen solution or by coating them on the preformed scaffold. ${ }^{14,71}$ Pore size and collagen concentration might also direct the mechanical properties of myoblast micro-environment and hence their differentiation ability, which was shown to be optimal on gels with a stiffness of around $12 \mathrm{kPa}^{49}$

\section{CONCLUSIONS}

We have described here a processing strategy that enabled us to obtain highly porous and anisotropic fibrillar collagen biomaterials, with pores patterned with regularly spaced ridges running all along the scaffold, via a topotactic transformation. The self-standing scaffolds exhibit unprecedented stiffness for macroporous pure collagen scaffolds in the wet state, sparing the use of any cross-linking technique. They showed high bioactivity toward NHDF and $\mathrm{C} 2 \mathrm{C} 12$ cells that can colonize these scaffolds without additional physical, chemical, or biological cues.

When compared to common cross-linking techniques, the elaborated topotactic self-assembly has the advantage of preserving the structure obtained from freeze-casting and producing a homogeneous scaffold. Besides, FBL scaffolds were less brittle with mechanical properties closer to mammalian soft tissues and demonstrated much higher cell adhesion.

The demonstrated ability to align cells could be of significant interest for muscle, tendon, or nerve regeneration. In particular, the pore size gradients generated by the freezecasting process could be used for the colonization and controlled differentiation of different types of cells and the generation of junctions between different tissues.

\section{ASSOCIATED CONTENT}

\section{S Supporting Information}

The Supporting Information is available free of charge on the ACS Publications website at DOI: 10.1021/acsami.9b03219.

Orientation of pore domains at two different positions of the scaffold; TEM pictures of the different structures observed in final scaffolds; comparison of two alternate processes on semithin sections; pictures of FBL and CXL scaffolds; degradation tests on FBL and CXL scaffolds; comparison on FBL and CXL scaffolds at different time points during 3 week culture of NHDFs; image of a $1.2 \mathrm{~mm}$ thick slice of a cross-linked scaffold; and SEM pictures of the outside of a lyophilized scaffold after freeze-casting (PDF)
Movies S1. SHG and fluorescence 3D reconstitution from confocal microscopy of collagen scaffold after fibrillogenesis and seeding with NHDFs. Movie S1A: Reconstitution of an exterior surface of the scaffold (AVI). Movie S1B: Reconstitution of cell gradient from a side of the scaffold (AVI). Movie S1C: Reconstitution of NHDFs on parallel walls with ridges inside the scaffold (AVI).

Movie S2. SHG and fluorescence 3D reconstitution from confocal microscopy of collagen scaffold after fibrillogenesis and seeding with $\mathrm{C} 2 \mathrm{C} 12$ myoblasts. Movie S2A: Reconstitution of the colonization through open pores at a scaffold extremity (AVI). Movie S2B: Reconstitution of a myoblasts gradient of colonization on a side of the scaffold (AVI).

\section{AUTHOR INFORMATION}

\section{Corresponding Authors}

*E-mail: lea.trichet@upmc.fr (L.T.).

*E-mail: francisco.fernandes@upmc.fr (F.M.F.).

ORCID 0

Cleo Parisi: 0000-0002-2907-4025

Gervaise Mosser: 0000-0002-9812-5340

Thibaud Coradin: 0000-0003-3374-5722

Francisco M. Fernandes: 0000-0002-6697-1470

Léa Trichet: 0000-0002-5797-0978

\section{Author Contributions}

The manuscript was written through contributions of all authors. All authors have given approval to the final version of the manuscript.

Notes

The authors declare no competing financial interest.

\section{ACKNOWLEDGMENTS}

The authors would like to thank Alba Marcellan, Costantino Creton, Jingwen Zhao, and Francisco Cedano for their help with the tensile testing experiments. Heng Lu, Yupeng Shi, and Christophe Hélary are kindly acknowledged for their help with cell culture. The authors also thank Jennifer Coridon and Julien Dumont for help with sample preparation using vibratome and image acquisitions using confocal fluorescence and SHG microscopy. C.R. was supported by a French Ministère de la Recherche fellowship. C.P. acknowledges funding from the Paris Ile-de-France region via the DIM RESPORE.

\section{REFERENCES}

(1) Barczyk, M.; Carracedo, S.; Gullberg, D. Integrins. Cell Tissue Res. 2010, 339, 269-280.

(2) Jokinen, J.; Dadu, E.; Nykvist, P.; Käpylä, J.; White, D. J.; Ivaska, J.; Vehviläinen, P.; Reunanen, H.; Larjava, H.; Häkkinen, L.; et al. Integrin-Mediated Cell Adhesion to Type I Collagen Fibrils. J. Biol. Chem. 2004, 279, 31956-31963.

(3) Hulmes, D. J. S. Collagen Diversity, Synthesis and Assembly. Collagen: Structure and Mechanics; Springer: New York, NY, 2008; pp $15-48$.

(4) Rieu, C.; Picaut, L.; Mosser, G.; Trichet, L. From Tendon Injury to Collagen-based Tendon Regeneration: Overview and Recent Advances. Curr. Pharm. Des. 2017, 23, 3483-3506.

(5) Giraud-Guille, M. M.; Mosser, G.; Helary, C.; Eglin, D. Bone Matrix like Assemblies of Collagen: From Liquid Crystals to Gels and Biomimetic Materials. Micron 2005, 36, 602-608. 
(6) Giraud-Guille, M.-M.; Nassif, N.; Fernandes, F. M. CollagenBased Materials for Tissue Repair, from Bio-Inspired to Biomimetic. Materials Design Inspired by Nature: Function through Inner Architecture; RSC Smart Materials; The Royal Society of Chemistry, 2013; pp 107-127.

(7) Cavallaro, J. F.; Kemp, P. D.; Kraus, K. H. Collagen Fabrics as Biomaterials. Biotechnol. Bioeng. 1994, 43, 781-791.

(8) Kishore, V.; Uquillas, J. A.; Dubikovsky, A.; Alshehabat, M. A.; Snyder, P. W.; Breur, G. J.; Akkus, O. In Vivo Response to Electrochemically Aligned Collagen Bioscaffolds. J. Biomed. Mater. Res. B Appl. Biomater. 2012, 100, 400-408.

(9) Juncosa-Melvin, N.; Boivin, G. P.; Galloway, M. T.; Gooch, C.; West, J. R.; Sklenka, A. M.; Butler, D. L. Effects of Cell-to-Collagen Ratio in Mesenchymal Stem Cell-Seeded Implants on Tendon Repair Biomechanics and Histology. Tissue Eng. 2005, 11, 448-457.

(10) Mudera, V.; Morgan, M.; Cheema, U.; Nazhat, S.; Brown, R. Ultra-Rapid Engineered Collagen Constructs Tested in Anin Vivo Nursery Site. J. Tissue Eng. Regen. Med. 2007, 1, 192-198.

(11) Barry, R. A.; Shepherd, R. F.; Hanson, J. N.; Nuzzo, R. G.; Wiltzius, P.; Lewis, J. A. Direct-Write Assembly of 3D Hydrogel Scaffolds for Guided Cell Growth. Adv. Mater. 2009, 21, 2407-2410.

(12) Deville, S. Freeze-Casting of Porous Ceramics: A Review of Current Achievements and Issues. Adv. Eng. Mater. 2008, 10, 155169.

(13) Chamberlain, L. J.; Yannas, I. V.; Arrizabalaga, A.; Hsu, H.-P.; Norregaard, T. V.; Spector, M. Early Peripheral Nerve Healing in Collagen and Silicone Tube Implants: Myofibroblasts and the Cellular Response. Biomaterials 1998, 19, 1393-1403.

(14) Riblett, B. W.; Francis, N. L.; Wheatley, M. A.; Wegst, U. G. K. Ice-Templated Scaffolds with Microridged Pores Direct DRG Neurite Growth. Adv. Funct. Mater. 2012, 22, 4920-4923.

(15) Asuncion, M. C. T.; Goh, J. C.-H.; Toh, S.-L. Anisotropic Silk Fibroin/Gelatin Scaffolds from Unidirectional Freezing. Mater. Sci. Eng. C 2016, 67, 646-656.

(16) Rouquerol, J.; Avnir, D.; Fairbridge, C. W.; Everett, D. H.; Haynes, J. M.; Pernicone, N.; Ramsay, J. D. F.; Sing, K. S. W.; Unger, K. K. Recommendations for the Characterization of Porous Solids. Pure Appl. Chem. 1994, 66, 1739-1758.

(17) Wegst, U. G. K.; Schecter, M.; Donius, A. E.; Hunger, P. M. Biomaterials by Freeze Casting. Philos. Trans. R. Soc. Math. Phys. Eng. Sci. 2010, 368, 2099-2121.

(18) Pawelec, K. M.; Husmann, A.; Best, S. M.; Cameron, R. E. Understanding Anisotropy and Architecture in Ice-Templated Biopolymer Scaffolds. Mater. Sci. Eng. C 2014, 37, 141-147.

(19) Madaghiele, M.; Sannino, A.; Yannas, I. V.; Spector, M. Collagen-Based Matrices with Axially Oriented Pores. J. Biomed. Mater. Res. A 2008, 85, 757-767.

(20) Caliari, S. R.; Ramirez, M. A.; Harley, B. A. C. The Development of Collagen-GAG Scaffold-Membrane Composites for Tendon Tissue Engineering. Biomaterials 2011, 32, 8990-8998.

(21) Pawelec, K. M.; Husmann, A.; Best, S. M.; Cameron, R. E. A Design Protocol for Tailoring Ice-Templated Scaffold Structure. J. $R$. Soc. Interface 2014, 11, 20130958.

(22) Schoof, H.; Apel, J. r.; Heschel, I.; Rau, G. n. Control of Pore Structure and Size in Freeze-Dried Collagen Sponges. J. Biomed. Mater. Res. 2001, 58, 352-357.

(23) Chamberlain, L. J.; Yannas, I. V.; Hsu, H.-P.; Strichartz, G. R.; Spector, M. Near-Terminus Axonal Structure and Function Following Rat Sciatic Nerve Regeneration through a Collagen-GAG Matrix in a Ten-Millimeter Gap. J. Neurosci. Res. 2000, 60, 666-677.

(24) Pawelec, K. M.; Husmann, A.; Wardale, R. J.; Best, S. M.; Cameron, R. E. Ionic Solutes Impact Collagen Scaffold Bioactivity. J. Mater. Sci. Mater. Med. 2015, $26,91$.

(25) Pawelec, K. M.; Wardale, R. J.; Best, S. M.; Cameron, R. E. The Effects of Scaffold Architecture and Fibrin Gel Addition on Tendon Cell Phenotype. J. Mater. Sci. Mater. Med. 2015, 26, 5349.

(26) Varley, M. C.; Neelakantan, S.; Clyne, T. W.; Dean, J.; Brooks, R. A.; Markaki, A. E. Cell Structure, Stiffness and Permeability of
Freeze-Dried Collagen Scaffolds in Dry and Hydrated States. Acta Biomater. 2016, 33, 166-175.

(27) Harley, B.; Leung, J.; Silva, E.; Gibson, L. Mechanical characterization of collagen-glycosaminoglycan scaffolds. Acta Biomater. 2007, 3, 463-474.

(28) Caliari, S. R.; Harley, B. A. C. Composite Growth Factor Supplementation Strategies to Enhance Tenocyte Bioactivity in Aligned Collagen-GAG Scaffolds. Tissue Eng. Part A 2013, 19, $1100-1112$.

(29) Lowe, C. J.; Reucroft, I. M.; Grota, M. C.; Shreiber, D. I. Production of Highly Aligned Collagen Scaffolds by Freeze-Drying of Self-Assembled, Fibrillar Collagen Gels. ACS Biomater. Sci. Eng. 2016, 2, 643-651.

(30) Murray, M. M.; Flutie, B. M.; Kalish, L. A.; Ecklund, K.; Fleming, B. C.; Proffen, B. L.; Micheli, L. J. The Bridge-Enhanced Anterior Cruciate Ligament Repair (BEAR) Procedure. Orthop. J. Sports Med. 2016, 4, 2325967116672176.

(31) Magarian, E. M.; Vavken, P.; Connolly, S. A.; Mastrangelo, A. N.; Murray, M. M. Safety of Intra-Articular Use of Atelocollagen for Enhanced Tissue Repair. Open Orthop. J. 2012, 6, 231-238.

(32) Fleming, B. C.; Magarian, E. M.; Harrison, S. L.; Paller, D. J.; Murray, M. M. Collagen Scaffold Supplementation Does Not Improve the Functional Properties of the Repaired Anterior Cruciate Ligament. J. Orthop. Res. 2010, 28, 703-709.

(33) Tidu, A.; Ghoubay-Benallaoua, D.; Lynch, B.; Haye, B.; Illoul, C.; Allain, J.-M.; Borderie, V. M.; Mosser, G. Development of Human Corneal Epithelium on Organized Fibrillated Transparent Collagen Matrices Synthesized at High Concentration. Acta Biomater. 2015, 22, $50-58$.

(34) Helary, C.; Abed, A.; Mosser, G.; Louedec, L.; Letourneur, D.; Coradin, T.; Giraud-Guille, M. M.; Meddahi-Pellé, A. Evaluation of Dense Collagen Matrices as Medicated Wound Dressing for the Treatment of Cutaneous Chronic Wounds. Biomater. Sci. 2015, 3, 373-382.

(35) Elliott, L. D. The Freezing Point Curve of the System WaterAmmonia. J. Phys. Chem. 1923, 28, 887-888.

(36) Christoph, S.; Kwiatoszynski, J.; Coradin, T.; Fernandes, F. M. Cellularized Cellular Solids via Freeze-Casting. Macromol. Biosci. 2016, 16, 182-187.

(37) De Sa Peixoto, P.; Deniset-Besseau, A.; Schanne-Klein, M.-C.; Mosser, G. Quantitative Assessment of Collagen I Liquid Crystal Organizations: Role of Ionic Force and Acidic Solvent, and Evidence of New Phases. Soft Matter 2011, 7, 11203.

(38) Besseau, L.; Giraud-Guille, M.-M. Stabilization of Fluid Cholesteric Phases of Collagen to Ordered Gelated Matrices. J. Mol. Biol. 1995, 251, 197-202.

(39) Gobeaux, F.; Mosser, G.; Anglo, A.; Panine, P.; Davidson, P.; Giraud-Guille, M.-M.; Belamie, E. Fibrillogenesis in Dense Collagen Solutions: A Physicochemical Study. J. Mol. Biol. 2008, 376, 15091522.

(40) Park, J.; Kim, D.-H.; Kim, H.-N.; Wang, C. J.; Kwak, M. K.; Hur, E.; Suh, K.-Y.; An, S. S.; Levchenko, A. Directed Migration of Cancer Cells Guided by the Graded Texture of the Underlying Matrix. Nat. Mater. 2016, 15, 792-801.

(41) Li, Y.; Asadi, A.; Monroe, M. R.; Douglas, E. P. pH effects on collagen fibrillogenesis in vitro: Electrostatic interactions and phosphate binding. Mater. Sci. Eng. C 2009, 29, 1643-1649.

(42) Picaut, L.; Trichet, L.; Ronsin, O.; Haye, B.; Génois, I.; Baumberger, T.; Mosser, G. Pure Dense Collagen Threads from Extrusion to Fibrillogenesis Stability. Biomed. Phys. Eng. Express 2018, 4, 035008.

(43) Tidu, A.; Ghoubay-Benallaoua, D.; Teulon, C.; Asnacios, S.; Grieve, K.; Portier, F.; Schanne-Klein, M.-C.; Borderie, V.; Mosser, G. Highly Concentrated Collagen Solutions Leading to Transparent Scaffolds of Controlled Three-Dimensional Organizations for Corneal Epithelial Cell Colonization. Biomater. Sci. 2018, 6, 1492-1502.

(44) Geiger, M. Collagen Sponges for Bone Regeneration with RhBMP-2. Adv. Drug Deliv. Rev. 2003, 55, 1613-1629. 
(45) Offeddu, G. S.; Ashworth, J. C.; Cameron, R. E.; Oyen, M. L. Multi-Scale Mechanical Response of Freeze-Dried Collagen Scaffolds for Tissue Engineering Applications. J. Mech. Behav. Biomed. Mater. 2015, 42, 19-25.

(46) Kanungo, B. P.; Gibson, L. J. Density-property relationships in collagen-glycosaminoglycan scaffolds. Acta Biomater. 2010, 6, 344353.

(47) Dagalakis, N.; Flink, J.; Stasikelis, P.; Burke, J. F.; Yannas, I. V. Design of an Artificial Skin. Part III. Control of Pore Structure. J. Biomed. Mater. Res. 1980, 14, 511-528.

(48) Chvapil, M. Collagen Sponge: Theory and Practice of Medical Applications. J. Biomed. Mater. Res. 1977, 11, 721-741.

(49) Engler, A. J.; Griffin, M. A.; Sen, S.; Bönnemann, C. G.; Sweeney, H. L.; Discher, D. E. Myotubes differentiate optimally on substrates with tissue-like stiffness. J. Cell Biol. 2004, 166, 877-887.

(50) Pieper, J. S.; Hafmans, T.; Veerkamp, J. H.; van Kuppevelt, T. $\mathrm{H}$. Development of tailor-made collagen-glycosaminoglycan matrices: EDC/NHS crosslinking, and ultrastructural aspects. Biomaterials 2000, 21, 581-593.

(51) Christoph, S.; Hamraoui, A.; Bonnin, E.; Garnier, C.; Coradin, T.; Fernandes, F. M. Ice-Templating Beet-Root Pectin Foams: Controlling Texture, Mechanics and Capillary Properties. Chem. Eng. J. 2018, 350, 20-28.

(52) Helary, C.; Ovtracht, L.; Coulomb, B.; Godeau, G.; GiraudGuille, M. Dense Fibrillar Collagen Matrices: A Model to Study Myofibroblast Behaviour during Wound Healing. Biomaterials 2006, 27, 4443-4452.

(53) Cukierman, E.; Pankov, R.; Stevens, D. R.; Yamada, K. M. Taking Cell-Matrix Adhesions to the Third Dimension. Science 2001, 294, 1708-1712.

(54) Del Amo, C.; Borau, C.; Movilla, N.; Asín, J.; García-Aznar, J. M. Quantifying 3D Chemotaxis in Microfluidic-Based Chips with Step Gradients of Collagen Hydrogel Concentrations. Integr. Biol. 2017, 9, 339-349.

(55) Moreno-Arotzena, O.; Borau, C.; Movilla, N.; VicenteManzanares, M.; García-Aznar, J. M. Fibroblast Migration in 3D Is Controlled by Haptotaxis in a Non-Muscle Myosin II-Dependent Manner. Ann. Biomed. Eng. 2015, 43, 3025-3039.

(56) Caliari, S. R.; Weisgerber, D. W.; Grier, W. K.; Mahmassani, Z.; Boppart, M. D.; Harley, B. A. C. Collagen Scaffolds Incorporating Coincident Gradations of Instructive Structural and Biochemical Cues for Osteotendinous Junction Engineering. Adv. Healthc. Mater. 2015, 4, 831-837.

(57) Caliari, S. R.; Harley, B. A. C. The Effect of Anisotropic Collagen-GAG Scaffolds and Growth Factor Supplementation on Tendon Cell Recruitment, Alignment, and Metabolic Activity. Biomaterials 2011, 32, 5330-5340.

(58) Gonnerman, E. A.; Kelkhoff, D. O.; McGregor, L. M.; Harley, B. A. C. The Promotion of HL-1 Cardiomyocyte Beating Using Anisotropic Collagen-GAG Scaffolds. Biomaterials 2012, 33, 88128821.

(59) Grier, W. K.; Iyoha, E. M.; Harley, B. A. C. The Influence of Pore Size and Stiffness on Tenocyte Bioactivity and Transcriptomic Stability in Collagen-GAG Scaffolds. J. Mech. Behav. Biomed. Mater. 2017, 65, 295-305.

(60) Lam, M. T.; Sim, S.; Zhu, X.; Takayama, S. The Effect of Continuous Wavy Micropatterns on Silicone Substrates on the Alignment of Skeletal Muscle Myoblasts and Myotubes. Biomaterials 2006, 27, 4340-4347.

(61) Gingras, J.; Rioux, R. M.; Cuvelier, D.; Geisse, N. A.; Lichtman, J. W.; Whitesides, G. M.; Mahadevan, L.; Sanes, J. R. Controlling the Orientation and Synaptic Differentiation of Myotubes with Micropatterned Substrates. Biophys. J. 2009, 97, 2771-2779.

(62) Huang, N. F.; Lee, R. J.; Li, S. Engineering of aligned skeletal muscle by micropatterning. Am. J. Transl. Res. 2010, 2, 43-55.

(63) Chen, S.; Kawazoe, N.; Chen, G. Biomimetic Assembly of Vascular Endothelial Cells and Muscle Cells in Microgrooved Collagen Porous Scaffolds. Tissue Eng. Part C Methods 2017, 23, 367-376.
(64) Bian, W.; Bursac, N. Engineered Skeletal Muscle Tissue Networks with Controllable Architecture. Biomaterials 2009, 30, 1401-1412.

(65) Hinds, S.; Bian, W.; Dennis, R. G.; Bursac, N. The Role of Extracellular Matrix Composition in Structure and Function of Bioengineered Skeletal Muscle. Biomaterials 2011, 32, 3575-3583.

(66) Powell, C. A.; Smiley, B. L.; Mills, J.; Vandenburgh, H. H. Mechanical Stimulation Improves Tissue-Engineered Human Skeletal Muscle. Am. J. Physiol.-Cell Physiol. 2002, 283, C1557-C1565.

(67) Lam, M. T.; Huang, Y.-C.; Birla, R. K.; Takayama, S. Microfeature Guided Skeletal Muscle Tissue Engineering for Highly Organized 3-Dimensional Free-Standing Constructs. Biomaterials 2009, 30, 1150-1155.

(68) Takahashi, H.; Shimizu, T.; Nakayama, M.; Yamato, M.; Okano, T. The Use of Anisotropic Cell Sheets to Control Orientation during the Self-Organization of 3D Muscle Tissue. Biomaterials 2013, $34,7372-7380$.

(69) Swasdison, S.; Mayne, R. Formation of Highly Organized Skeletal Muscle Fibers in Vitro. Comparison with Muscle Development in Vivo. J. Cell Sci. 1992, 102, 643-652.

(70) Goody, M. F.; Sher, R. B.; Henry, C. A. Hanging on for the Ride: Adhesion to the Extracellular Matrix Mediates Cellular Responses in Skeletal Muscle Morphogenesis and Disease. Dev. Biol. 2015, 401, 75-91.

(71) Rayagiri, S. S.; Ranaldi, D.; Raven, A.; Mohamad Azhar, N. I. F.; Lefebvre, O.; Zammit, P. S.; Borycki, A.-G. Basal Lamina Remodeling at the Skeletal Muscle Stem Cell Niche Mediates Stem Cell Self-Renewal. Nat. Commun. 2018, 9, 1075. 